\title{
Important Aspects of Human Behavior in Road Traffic Accidents
}

\author{
Ram Lakhan ${ }^{1} \quad$ Ranabir Pal ${ }^{2} \quad$ Arushi Baluja $^{3} \quad$ Luis Rafael Moscote-Salazar ${ }^{4} \quad$ Amit Agrawal $^{5}$
}

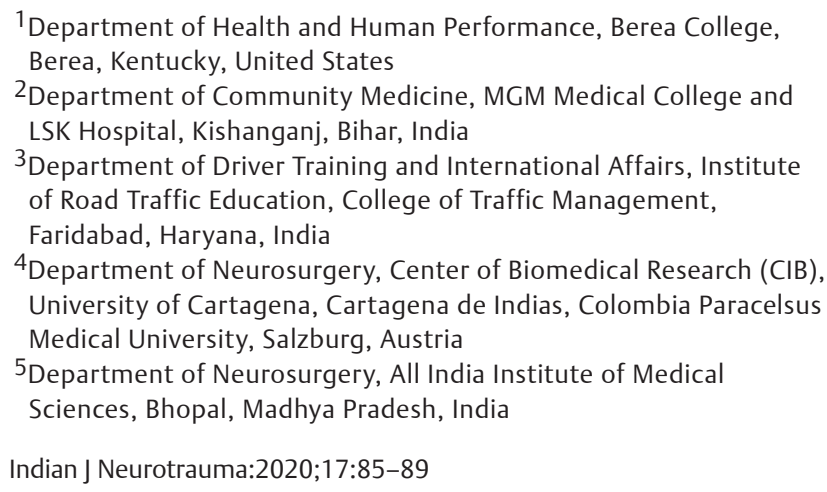

\author{
Address for correspondence Amit Agrawal, MCh, Department of \\ Neurosurgery, All India Institute of Medical Sciences, Saket Nagar, \\ Bhopal 462020, Madhya Pradesh, India \\ (e-mail: dramitagrawal@gmail.com).
}

\begin{abstract}
Keywords

- road traffic accidents

- human behavior

- public health

Worldwide road traffic accidents have been increasing. Human behaviors and environmental factors are often responsible for such events. This being a serious public health concern, public health interventions are needed to minimize the rate of road traffic accidents. We aimed to identify broader human behaviors, sociodemographic factors, and environmental factors associated with the risk of road traffic accidents. We searched for the relevant studies in electronic database including PubMed, Cochrane, Web of Science, Google Scholar, and World Health Organization global health library. In addition, a manual search was also performed. Findings from scientific literature were presented in a summative form. Young age, male gender, speed, influence of substance, use of mobile phone, driving experience, temperament, attitude, aggression, stress, anxiety, emotionality, fatigue, lack of sleep, and road conditions were found closely associated with a risk of road traffic accidents. Despite having substantial driving training and ability to handling motor vehicles, professional drivers such as bus and taxi drivers are very vulnerable to road traffic accidents. This study reports that the increasing prevalence of road traffic accidents can be addressed significantly by applying behavior change theories. The health belief model was found useful in promoting safer driving.
\end{abstract}

\section{Introduction}

Effective solutions to road traffic accidents require input from the fields of both engineering sciences and behavioral sciences. However, behavioral scientists encounter several methodological barriers in researching this crucial area of public health. Factors including lack of control for driver exposure and driver experience, difficulties in observing actual driving behavior, and the problems associated with recording and analyzing accident and violation rates possess limitations in researching behavioral dimensions of road safety and accidents. ${ }^{1}$ Insights into road safety behavior are critical in preventing and mitigating the morbidity and mortality associated with road traffic accidents. ${ }^{2}$ In this backdrop, the purpose of this article is to describe the role of behavior change in injury prevention and illustrate how the application of selected behavior change theories to injury problems, within the context of a health promotion framework, can contribute to the enhancement of injury prevention programs. ${ }^{3}$
DOI https://doi.org/

10.1055/s-0040-1713079

ISSN 2277-954X.
(C2020 Neurotrauma Society of India
License terms

()(1) $\Theta \circledast$ 


\section{Behavior Change and Road Safety}

Behavior change is often associated with complex social, political, and economic dimensions. This is evident from smoking, diet, alcohol consumption, physical inactivity, and other health-related behaviors. However, unlike behavior change entailed in health-related behaviors, road safety behavior often does not entail such complex social, political, and economic dimensions that may prevent people to change their behavior to more healthy ways of living. ${ }^{2}$ For example, changes in smoking, dietary changes, alcohol consumption, and physical activity are processes and practices embedded in social life, not one-off events triggered by information or prevented by remedying information deficits. Neither are these processes a consequence of people applying a rational calculus to their own actions. ${ }^{2}$ Changing road safety behaviors is therefore an attractive policy approach. Research into the psychological aspects of driving behavior is essential to an overall approach to road safety issues. However, the problems of conducting such research are not easily addressed. Controlling for the effects of experience and exposure within studies of the general population is rather difficult, ${ }^{4}$ and the analysis of actual driving behavior and accidents is also fraught with problems. One way of attempting to compensate for these problems is to limit the scope of research to groups of road users that allow for a more careful study of psychological factors. Examples of this approach that have been successful include the study of long-distance truck drivers ${ }^{5}$ and taxi drivers. Research into taxi drivers is not just valuable because of its possible usefulness to general road safety research but it is also valuable in its own right. Taxi drivers play a crucial role in the social and economic functions of modern society. Their contribution to the day-to-day operation of the business world and tourism is of considerable significance, as is their general social function as a mean of transport for those who are unable to use other modes of public or private transport. In terms of general road safety, the use of taxis is a key alternative to drink-driving, and hence taxis provide a service of potentially great indirect benefit to overall road safety. ${ }^{1}$ Many studies have shown that human behavioral factors collectively represent the main cause of road traffic crashes, and their remedial measures can go a long way to help prevent road traffic injuries (RTIs). ${ }^{6-11} \mathrm{~A}$ growing body of work is emerging that demonstrates the positive impact of using behavioral science approaches to both understand and reduce injury risk behaviors. ${ }^{12-16}$

\section{Epidemiology of Road Traffic Accidents}

Numerous epidemiological studies have demonstrated that human behavior accounts for more than $85 \%$ of road accidents. ${ }^{17-19}$ The World Health Organization report attributes $71 \%$ of road accidents to human factors. ${ }^{20}$ Application of behavior change theories can significantly reduce the rate of road accidents and resultant injuries. ${ }^{21}$

\section{Common Risks of Road Accidents}

\section{Speed}

Speed is the most common factor that leads to accidents. The literature indicates that both human and environmental factors can affect the speed of the motor vehicle. Among human factors, age, gender, alcohol consumption and its level, and number of passengers in a vehicle are often found responsible. While motor vehicle condition, its power, its speed, road layout, surface quality, traffic density, allowed speed, time of the day, and weather conditions significantly affect speed..$^{22}$ Influence of substance: approximately $20 \%$ road accidents in high-income countries and 33 to $69 \%$ in low-income countries take place under the influence of alcohol. ${ }^{23}$ However, studies from Norwegian demonstrate that the professional drivers who also drive under the influence of alcohol have a lower rate of accidents than the nonprofessional drivers. ${ }^{24}$

\section{Fatigue}

Fatigue is an important risk factor that has been found to be associated with road accidents. Young drivers in the age range of 16 to 29 years, males, shift workers, people with sleep apnea, drivers who had less than 5 hours of sleep, and drivers who drive between 2:00 a.m. to 5:00 a.m. were found to be more affected with fatigue. ${ }^{22}$ Professional drivers who work on a tight schedule were found at a higher risk of having fatigue. ${ }^{22}$ Research suggests that drivers experience same influence on their driving with fatigue impairment, as they would do with alcohol consumption. ${ }^{25}$

\section{Handheld Mobile Telephone}

Numerous studies have shown that the use of mobile phone leads to a bigger distraction in driving. Across the world, a high number of accidents had been attributed to this risky behavior. $^{22}$

\section{Sociodemographic Factors Affecting Behavior}

\section{Age and Gender}

Age and male gender have been found significantly associated with risky behaviors. Studies conducted in low- as well as high-income countries have found that younger people compared with older age group, and males engage in high-risk driving behaviors. ${ }^{26}$ In those studies, it was observed that male drivers compete with other drivers, ignore signal lights, do not fasten the seat belt, and overtake at a higher rate than their female counterparts and take longer time to return in the proper lane. ${ }^{27,28}$ Males also violate rules more than females and encounter higher numbers of fatal accidents due to poor compliance with traffic rules. 27,28 Association between gender, age, time of driving in the day, and road conditions were also observed in several international studies, and it was found that female are much safer drivers in all road conditions (wet/dry, straight/curbed, rural/urban) and time of day (day/night). Females become much 
safer drivers at a much higher rate than their male counterparts as they get older. ${ }^{29,30}$ Females were also found keeping a safer distance between other vehicles on the road, whereas male drivers are much prone to drive in close proximity to other vehicles. ${ }^{31}$ Males between 31 and 40 years of age were found to be more traffic rules violators than any other age and gender group. ${ }^{32}$

\section{Behavior of Professional Drivers}

This section talks about the behavior of professional drivers, mainly bus and taxi drivers. The experience of driving makes these professionals more comfortable in driving in all situations. Once professional drivers start seeing themselves as expert drivers, the risk-taking behavior also increases among them. They are more likely to use mobile phone for communication and engage in other tasks such as setting the radio station and so on, which leads to a huge distraction in their driving. ${ }^{33}$ Mainly high workload, fatigue, sleep deprivation, stress, and dual tasking while operating the vehicle causes road accidents in professional drivers. ${ }^{34,35}$ Professional drivers have shown poor intention of wearing a seat belt and have been found driving in fatigue and under the influence of alcohol in middle- and low-income countries. ${ }^{36,37}$ It is well understood in the existing literature that when drivers perceive a higher level of self-control, their behavioral intentions, motivation, and priorities for safety rules get influenced negatively. ${ }^{38}$ Professional drivers are more exposed to traffic hazards as they spent more time in driving than nonprofessionals and get desensitized with the hazards and undermine risks. ${ }^{36,39}$ Professional drivers who undergo a training receive a different level of driving license, social image of an expert driver, low level of driving anxiety, and more driving experience. All these factors put in their minds that they are more skilled drivers. This negative confidence brings vulnerability in their behaviors, which indirectly promotes risk-taking behaviors. ${ }^{40-42}$

\section{Bus Drivers}

In addition to experiencing the same environmental traffic conditions, bus drivers carry additional constraints that are imposed by the vehicle characteristics, concern for passengers and their comfort/safety, and reaching on the scheduled time. Bus driving has been classified as a highly stressful occupation. Often, the associated physical and psychological factors result in poor driving performance. ${ }^{43}$ People perceive that a higher level of control and their behavioral intentions, motivation, and priorities regarding safety could be influenced in a safety-reducing direction. ${ }^{38}$ Personality trait, especially attitude of the driver, has been found highly responsible for risky driving, failure to follow traffic rules, and number of road accidents in studies conducted in several countries. ${ }^{43-45}$

\section{Taxi Drivers}

Compared with bus driving, taxi driving has been seen to be a strenuous occupation. However, research findings have shown that taxi drivers face a significantly higher risk of crime that impacts their driving negatively. Taxi driving is based on an intermittent reward system, that is, their earning is not fixed like bus drivers, and therefore they have even greater pressure of working long hours and in unfavorably difficult situations. Compared with bus drivers, taxi drivers develop communicable, noncommunicable, and chronic diseases at a much faster rate and in a higher magnitude due to frequent contact with passengers from all walks. ${ }^{46}$ Unhealthy lifestyle is much common among taxi drivers, which makes them prone to obesity, heart disease, type 2 diabetes, and even HIV/AIDs infection. ${ }^{46,47}$

\section{Other Factors}

\section{Reckless and Fun Ride}

Some drivers look for gratification, adventure, joy, and pride in their driving. Mainly, these drivers are not professional; they lack adequate training and engage in high risk-taking behavior. Alcohol consumption is also very prevalent among this group, which, on the one side, impairs their judgment and concentration, and on the other side, elevates their mood, making them more vulnerable to fatal accidents. ${ }^{48,49}$

\section{Experience}

Experienced drivers gain better driving skills, attitude, and behavior, whereas drivers who lack driving experience are more susceptible to making mistakes. ${ }^{24}$

\section{Personality Traits}

Personality traits including risk propensity, sensation-seeking, conscientiousness, openness to experience, emotional stability, extraversion, and agreeableness exert influence on drivers' driving attitude and behavior while driving..$^{50}$

\section{Emotions: Anger and Anxiety}

Emotions, mainly anger and anxiety, have also found to be significantly associated with a higher chance of traffic accidents. Often, drivers charged with emotions find difficulty in concentrating on their driving and they become victims of making mistake. ${ }^{51,52}$

\section{Need for Behavior Change}

Evidences strongly suggest that road traffic accidents can be greatly minimized by bringing about changes in human behaviors and the associated psychological and structural factors. Multiple behavior change theories have been successfully implied in various driving-related risky health behaviors across the world. The health belief model has been found to be more appropriate in addressing human behaviors and educating drivers for the risk as well as prevention. ${ }^{53,54}$ In addition, environmental changes are also needed to address the high rate of road accidents.

\section{Conclusion}

Road traffic accidents are rapidly increasing in low- and middle-income countries; however, public health interventions 
and related research are very minimal in these countries. Behavior health theories have been applied in more advanced nations, but application of such behavior interventions is minimal in low- and middle-income nations. This study provides a brief idea of factors that contribute to road traffic accidents, including differences between professional and nonprofessional drivers, association with sociodemographic factors, and vulnerable population. This information can be used to guide appropriate behavior change theory and plan to promote safer driving and prevent road traffic accidents.

\section{Conflict of Interest}

None declared.

\section{References}

1 Dalziel J, Job S. Taxi Drivers and Road Safety: A Report to the Federal Office of Road Safety 1997b. Retrieved on May 23, 2020. Available at: https://www.infrastructure.gov.au/roads/ safety/publications/1997/pdf/taxi_drivers.pdf.

2 Kelly MP, Barker M. Why is changing health-related behaviour so difficult? Public Health 2016;136:109-116

3 Gielen AC, Sleet D. Application of behavior-change theories and methods to injury prevention. Epidemiol Rev 2003;25:65-76

4 Brown ID. Exposure and experience are a confounded nuisance in research on driver behaviour. Accid Anal Prev 1982;14:345-352

5 Hamelin P. Lorry driver's time habits in work and their involvement in traffic accidents. Ergonomics 1987;30(9):1323-1333

6 Bener A, Al Humoud SMQ, Price P, et al. The effect of seatbelt legislation on hospital admissions with road traffic injuries in an oil-rich, fast-developing country. Int J Inj Contr Saf Promot 2007;14(2):103-107

7 Bener A, Al Maadid MGA, Özkan T, Al-Bast DAE, Diyab KN, Lajunen T. The impact of four-wheel drive on risky driver behaviours and road traffic accidents. Transp Res, Part F Traffic Psychol Behav 2008;11:324-333

8 Bener A, Burgut HR, Sidahmed H, AlBuz R, Sanya R, Khan WA. Road traffic injuries and risk factors. Calif J Health Promot 2009; 7:92-101

9 Bener A, Crundall D. Role of gender and driver behaviour in road traffic crashes. Int J Crashworthiness 2008;13:331-336

10 Bener A, Lajunen T, Özkan T, Haigney D. The effect of mobile phone use on driving style and driving skills. Int J Crashworthiness 2006;11:459-465

11 Bener A, Rahman YSA, Mitra B. Incidence and severity of head and neck injuries in victims of road traffic crashes: In an economically developed country. Int Emerg Nurs 2009;17(1):52-59

12 Gielen AC. Injury and Domestic Violence Prevention. New York, NY Elsevier; 2002

13 Gielen AC, Girasek DC. Integrating perspectives on the prevention of unintentional injuries. In: Schneiderman N, Speers MA, Silva JM, Tomes H, Gentry JH, eds. Integrating Behavioral and Social Sciences with Public Health. Washington, DC: American Psychological Association; 2001:203-230

14 Rothengatter TE, Vaya EC, Traffic and Transport Psychology: Theory and Application. Oxford: Pergamon; 1997

15 Sleet DA, Hopkins K, Singer HH, Bibliography of Behavioral Science Research in Unintentional Injuries. Atlanta, GA: National Center for Injury Prevention and Control; 2003

16 Sleet DA, Lonero L, Behavioral strategies for reducing traffic crashes. In: Encyclopedia of Public Health. New York, NY: Macmillan; 2002 105-107
17 Peden M, Scurfield R, Sleet D, et al. World Report on Road Traffic Injury Prevention. Geneva: World Health Organization; 2004

18 McKenna FP. It won't happen to me: unrealistic optimism or illusion of control? Br J Psychol 1993;84:39-50

19 Petridou E, Moustaki M. Human factors in the causation of road traffic crashes. Eur J Epidemiol 2000;16(9):819-826

20 Elvik R, Høye A, Vaa T, Sørensen M, The Handbook of Road Safety Measures. Bingley, England: Emerald; 2009

21 Ulleberg P, Rundmo T. Personality, attitudes and risk perception as predictors of risky driving behaviour among young drivers. Saf Sci 2003;41:427-443

22 Mohan D, Tiwari G, Khayesi M, Nafukho FM. Road Traffic Injury Prevention: Training Manual. Geneva: World Health Organization; 2006

23 Lemoine P, Ohayon M. Abuse of psychotropic drugs during driving. Encephale 1996;22(1):1-6

24 Nordfjærn T, Jørgensen SH, Rundmo T. Safety attitudes, behaviour, anxiety and perceived control among professional and non-professional drivers. J Risk Res 2012;15:875-896

25 Dalziel JR, Job RFS. A reconsideration of the relationship between driving experiences, accident record and optimism bias. In: 23rd Internation Congress of Applied Psychology, Madrid 1994

26 Hassen A, Godesso A, Abebe L, Girma E. Risky driving behaviors for road traffic accident among drivers in Mekele city, Northern Ethiopia. BMC Res Notes 2011;4:535

27 Romano EO, Peck RC, Voas RB. Traffic environment and demographic factors affecting impaired driving and crashes. J Safety Res 2012;43(1):75-82

28 Vlahogianni EI, Golias JC. Bayesian modeling of the microscopic traffic characteristics of overtaking in two-lane highways. Transp Res, Part F Traffic Psychol Behav 2012;15:348-357

29 Morgan A, Mannering FL. The effects of road-surface conditions, age, and gender on driver-injury severities. Accid Anal Prev 2011;43(5):1852-1863

30 Russo F, Biancardo SA, Dell'Acqua G. Road safety from the perspective of driver gender and age as related to the injury crash frequency and road scenario. Traffic Inj Prev 2014;15(1):25-33

31 Alexander J, Barham P, Black I. Factors influencing the probability of an incident at a junction: results from an interactive driving simulator. Accid Anal Prev 2002;34(6):779-792

32 Akaateba MA, Amoh-Gyimah R. Driver attitude towards traffic safety violations and risk taking behaviour in Kumasi: the gender and age dimension. Int J Traffic Transp Eng 2013;3: 479-494

33 Collet C, Guillot A, Petit C. Phoning while driving I: a review of epidemiological, psychological, behavioural and physiological studies. Ergonomics 2010;53(5):589-601

34 Dorn L, Stephen L, af Wåhlberg A, Gandolfi J. Development and validation of a self-report measure of bus driver behaviour. Ergonomics 2010;53(12):1420-1433

35 Taylor AH, Dorn L. Stress, fatigue, health, and risk of road traffic accidents among professional drivers: the contribution of physical inactivity. Annu Rev Public Health 2006;27:371-391

36 Lund IO, Rundmo T. Cross-cultural comparisons of traffic safety, risk perception, attitudes and behaviour. Saf Sci 2009;47:547-553

37 Nordfjærn T, Rundmo T. Perceptions of traffic risk in an industrialised and a developing country. Transp Res, Part F Traffic Psychol Behav 2009;12:91-98

38 Moen BE. Determinants of safety priorities in transport-The effect of personality, worry, optimism, attitudes and willingness to pay. Saf Sci 2007;45:848-863

39 Nordfjærn T, Jørgensen S, Rundmo T. A cross-cultural comparison of road traffic risk perceptions, attitudes towards traffic safety and driver behaviour. J Risk Res 2011;14:657-684 
40 Jackson L, Chapman P, Crundall D. What happens next? Predicting other road users' behaviour as a function of driving experience and processing time. Ergonomics 2009;52(2):154-164

41 Walton D. Examining the self-enhancement bias: professional truck drivers' perceptions of speed, safety, skill and consideration. Transp Res, Part F Traffic Psychol Behav 1999;2:91-113

42 Zhang W, Huang YH, Roetting M, Wang Y, Wei H. Driver's views and behaviors about safety in China-what do they NOT know about driving? Accid Anal Prev 2006;38(1):22-27

43 Md Rohani M, Buhari R. Bus Driver: Factors that influences behaviour. In: 9th International Conference of Geotechnical and Transportation Engineering (GEOTROPIKA) and 1st International Conference on Construction and Building Engineering (ICONBUILD) - GEOCON2013, Johor Bahru, Malaysia, 2013. Retrieved on May 23, 2020 at: http://eprints. uthm.edu.my/id/eprint/4565/1/ID180.pdf.

44 Mohamed N, Yusoff MF, Othman I, Zulkipli ZH, Osman MR. An Impact Assessment of Banning Wee-Hour Express Bus Operation. MIROS, Kuala Lumpur, 2009. Retrieved on May 23, 2020 at: http://dx.doi.org/10.1136/ip.2010.029215.296

45 Osman MR, Sarani R, Zulkipli ZH, Paiman NF. The effect of driver management system according to SHE COP in reducing speed violations 2009;11

46 Dahl S, Kaerlev L, Jensen A, et al. Hospitalization for lifestyle related diseases in long haul drivers compared with other truck drivers and the working population at large. Work 2009;33(3):345-353

47 Ramukumba TS, Mathikhi MS. Health assessment of taxi drivers in the city of Tshwane. Curationis 2016;39(1):e1-e7

48 Borgialli DA, Hill EM, Maio RF, Compton CP, Gregor MA. Effects of alcohol on the geographic variation of driver fatalities in motor vehicle crashes. Acad Emerg Med 2000;7(1):7-13

49 Eiksund S. A geographical perspective on driving attitudes and behaviour among young adults in urban and rural Norway. Saf Sci 2009;47:529-536

50 Henning JB, Stufft CJ, Payne SC, Bergman ME, Mannan MS, Keren N. The influence of individual differences on organizational safety attitudes. Saf Sci 2009;47:337-345

51 Backer-Grøndahl A, Fyhri A, Ulleberg P, Amundsen AH. Accidents and unpleasant incidents: worry in transport and prediction of travel behavior. Risk Anal 2009;29(9):1217-1226

52 Rundmo T, Nordfjærn T, Iversen HH, Oltedal S, Jørgensen SH. The role of risk perception and other risk-related judgements in transportation mode use. Saf Sci 2011;49:226-235

53 Glanz K, Rimer BK, Viswanath K, Health Behavior and Health Education: Theory, Research, and Practice. San Francisco, CA: John Wiley \& Sons; 2008

54 McGinnis JM, Williams-Russo P, Knickman JR. The case for more active policy attention to health promotion. Health Aff (Millwood) 2002;21(2):78-93 